Andrew G. Davies

Arnold R. Cowen

Stephen M. Kengyelics

Janet Moore

Mohan U. Sivananthan

\title{
Do flat detector cardiac X-ray systems convey advantages over image-intensifier-based systems? Study comparing $\mathrm{X}$-ray dose and image quality
}

Due to an error in publishing, the figures in this manuscript have been reproduced incorrectly. All figure numbers and captions are correct, but the graph for Fig. 1 appears under the caption for Fig. 3 and visa versa. Similarly, the graphs for Figs. 2 and 4 are transposed.

The online version of the original article can be found at http://dx.doi.org/10.1007/s00330006-0458-0.

A. G. Davies $(\bowtie) \cdot$ A. R. Cowen · S. M. Kengyelics

Academic Unit of Medical Physics, University of Leeds,

Worsley Building, Clarendon Way, Leeds, LS2 9JT, UK

e-mail: A.G.Davies@leeds.ac.uk

Tel.: +44-113-3923542

Fax: $+44-113-2347619$

J. Moore $\cdot$ M. U. Sivananthan

Yorkshire Heart Centre,

The General Infirmary at Leeds,

Leeds, LS1 3EX, UK 